NASA Technical Memorandum 107513

AIAA-97-3141

\title{
Numerical Study of Stratified Charge Combustion in Wave Rotors
}

M. Razi Nalim

Lewis Research Center

Cleveland, Ohio

Prepared for the

33rd Joint Propulsion Conference and Exhibit cosponsored by AIAA, ASME, SAE, and ASEE

Seattle, Washington, July 6-9, 1997

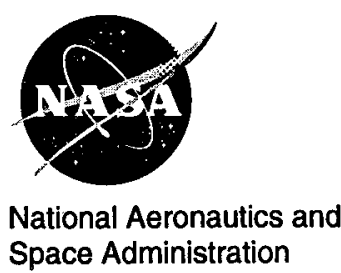


. 


\title{
NUMERICAL STUDY OF STRATIFIED CHARGE COMBUSTION IN WAVE ROTORS
}

\author{
M. Razi Nalim ${ }^{\dagger}$ \\ National Research Council \\ NASA Lewis Research Center \\ Cleveland, Ohio, USA
}

\begin{abstract}
$\underline{\text { Abstract }}$
A wave rotor may be used as a pressure-gain combustor effecting non-steady flow, and intermittent, confined combustion to enhance gas turbine engine performance. It will be more compact and probably lighter than an equivalent pressure-exchange wave rotor, yet will have similar thermodynamic and mechanical characteristics. Because the allowable turbine blade temperature limits overall fuel/air ratio to sub-flammable values, premixed stratification techniques are necessary to burn hydrocarbon fuels in small engines with compressor discharge temperature well below autoignition conditions. One-dimensional, unsteady numerical simulations of stratified-charge combustion are performed using an eddy-diffusivity turbulence model and a simple reaction model incorporating a flammability limit temperature. For good combustion efficiency, a stratification strategy is developed which concentrates fuel at the leading and trailing edges of the inlet port. Rotor and exhaust temperature profiles and performance predictions are presented at three representative operating conditions of the engine: full design load, $40 \%$ load, and idle. The results indicate that peak local gas temperatures will result in excessive temperatures within the rotor housing unless additional cooling methods are used. The rotor itself will have acceptable temperatures, but the pattern factor presented to the turbine may be of concern, depending on exhaust duct design and duct-rotor interaction.
\end{abstract}

\section{Introduction}

A wave rotor is a device that utilizes unsteady wave motion to exchange energy by direct work action between fluids, which may be chemically inert or reacting. It consists of a number of channels arranged about an axis. By rotation, the ends of the channels are periodically ported to high and low pressure manifolds (ducts) which generate and utilize waves in the channels. Because the number of channels is large, the

\footnotetext{
${ }^{\dagger}$ National Research Council - NASA Research Associate at Lewis Research Center, AIAA Member, ASME Member.
}

flow in the ducts is practically steady, and is directed to other steady flow components. An important feature is that as gases of a wide temperature range flow through the rotor, the mean temperature of the channel wall is lower than the highest gas temperature. Rotational speed is low relative to conventional turbomachines, and the geometry is usually simpler, allowing greater strength and lower cost. For detailed descriptions of wave rotor principles and applications see Refs. 1-3.

A wave rotor acting as a pressure exchanger can be used (together with a conventional combustor) as a topping unit to enhance the performance of a gas turbine engine. Fundamental thermodynamics ${ }^{4}$ and detailed simulations ${ }^{5-7}$ based on validated codes indicate a substantial pressure gain possible between the compressor and the turbine. This pressure gain could also be obtained using an internal-combustion wave rotor. In this case, combustion occurs sequentially within the wave channels, each channel being periodically charged and discharged as it rotates past properly sized and timed inlet and outlet ports. Simplified combustion and wave processes are illustrated in the wave rotor sketch in Fig. 1. By accomplishing combustion on the rotor, the external combustor needed in a pressure-exchanger topping cycle is eliminated, as is the associated ducting, which might be long and unmanageably hot in certain designs.

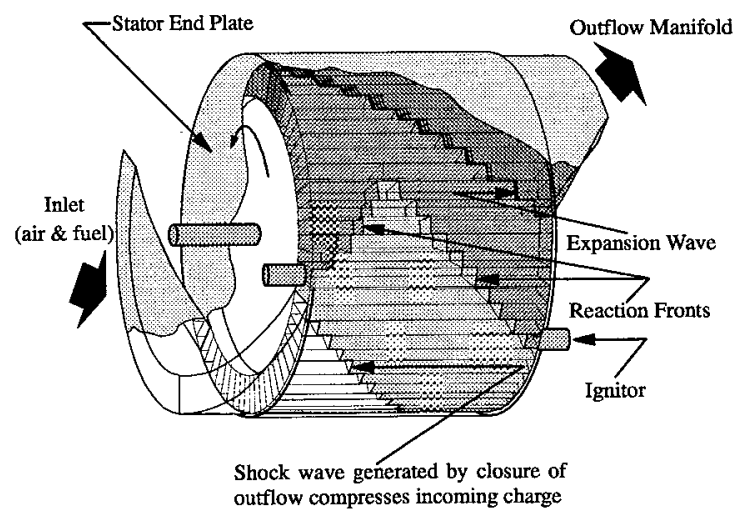

Fig. 1 Internal-combustion wave rotor schematic 


\section{Objectives}

A rapid and reliable mode of combustion is desired to minimize rotor size and losses. For small engines with relatively low inlet temperature $(<800 \mathrm{~K})$, a premixed turbulent combustion mode is envisaged. ${ }^{8}$ With higher air temperature, autoignited modes (detonation or nonpremixed combustion) become possible. In a previous study, ${ }^{9}$ deflagrative and detonative premixed modes were simulated using a one-dimensional CFD code with a simple combustion model. Single design point computations were performed assuming uniform inlet mixtures with the desired fuel energy content, without consideration of the flammability limits of real fuels over the operating range of the engine. This limitation was necessitated by the use of a single reaction progress variable to model heat release.

This paper reports the extension of this model to represent multiple species and reaction steps, and the incorporation of a flammability-limited combustion model to simulate combustor operation over a wide range. This study is limited to premixed turbulent combustion ignited by residual and reinjected hot gas. More specifically, this model is used to examine the possibility of operating a small turboshaft engine (2.2 $\mathrm{kg} / \mathrm{s}$ ) near sea level using pressure-gain, wave-rotor combustion. Many of the limitations of onedimensional simulations and simplified combustion and turbulence models discussed in Ref. 9 also apply in this study. Real combustion fronts are non-planar and are controlled by phenomena occurring at much smaller scales than can be resolved in these simulations. Available data on flammability limits and flame propagation rates are used to attempt to bound the wave rotor design parameters.

Under all operating conditions of a gas turbine engine the overall fuel-air ratio is very lean, usually below the lean flammability limit of typical fuels. This necessitates the use of a richer primary zone for stable combustion in conventional combustors, with additional air being mixed in downstream to bring the overall mixture to the lean condition and temperature that is acceptable by the turbine.

In wave rotor combustion, a similar strategy is necessary. It consists of separating the inlet air into a number of premixed sectors fueled by separate fuel injectors, enriching sectors that supply the zones where combustion is initiated. As load varies, injectors are modulated to maintain flammable mixture or are turned off. This will probably require microprocessor control of fuel injection, although no more complex than are used on modern IC engines. Simulation of the combustion of such stratified mixtures required the present model.
The internal-combustion wave-rotor model will be presented first, consisting of governing equations and the method of solution. The design of a wave rotor for the specific engine application is then discussed, and simulations are presented for full design load, part load, and idle conditions of operation of the engine. Feasibility issues and foreseen design challenges are also discussed.

\section{Computational Model and Solution Method}

The computational model consists of a representative wave rotor channel interacting with the upstream compressor, downstream turbine, channel walls, leakage cavity, and hot-gas reinjection duct (Fig. 2), as in Ref. 9. The leakage cavity represents space within the rotor housing which can exchange gas with the channels via the end gaps between the rotor and the casing endwalls. The reinjection duct takes hot combustion gas from channels at high pressure for ignition of fresh mixture in other channels. The total pressure and temperature delivered by the compressor is specified at each operating condition and no compressor model is used. The turbine is modeled as a choked valve with a fixed area which produces a back pressure matched to the flow rate. The channel walls are divided into axial segments matching the channel computational cells. Each segment exchanges heat with the corresponding fluid cell and with the leakage cavity, but not with adjacent segments (i.e., no longitudinal conduction).

\section{Channel Governing Equations}

Extension of the model to multiple species and multiple reactions allows the simulation of non-uniform mixtures. Calorically perfect gas is assumed, necessitating use of a constant approximate specific heat and molecular weight. The governing equations for an arbitrary number of $\boldsymbol{n}$ species and $m$ reactions are given below, consisting of total mass, momentum, and energy conservation equations, and $(n-1)$ equations for masses of all species but one which is determined from

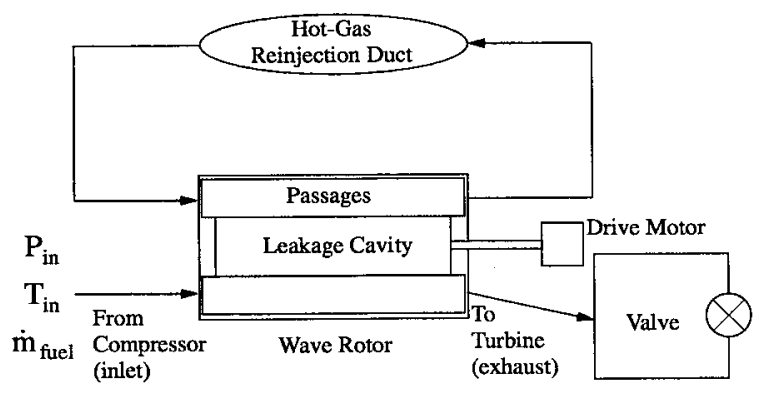

Fig. 2 System simulation schematic 
total mass. A species may be a single chemical compound, or a substance (such as air) which can be accounted for as a combination of compounds in fixed proportions, so that fewer equations need to be solved.

In non-dimensional form the equations are:

$$
\frac{\partial \bar{w}}{\partial t}+\frac{\partial \bar{F}(\bar{w})}{\partial x}=\bar{S}(\bar{w})
$$

where

$$
\bar{w}=\left[\begin{array}{c}
\rho \\
\frac{\rho u}{p}+\frac{\rho u^{2}}{2}+\sum_{i=1}^{n} \rho z_{i} q_{i} \\
\rho z_{i} \\
(i=1, n-1)
\end{array}\right]
$$

and

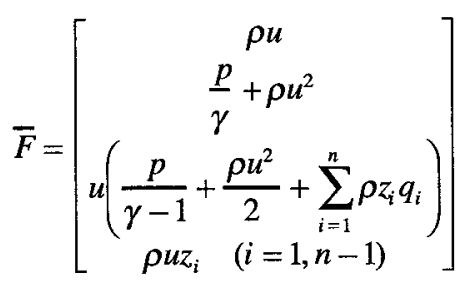

The distance, $x$ has been normalized by the passage length, $L$. The time, $t$ has been normalized by the characteristic wave transit time, $L / a^{*}$, where $a^{*}$ is the speed of sound at a chosen reference state. The pressure, $p$ and density, $\rho$ have been normalized by their respective reference values and the axial velocity, $u$ has been normalized by $a^{*}$. The mass fraction of species $i$ is $z_{i}$ and its chemical energy contribution is $q_{i}$. The ratio of specific heats is denoted by $\gamma$.

The source vector is:

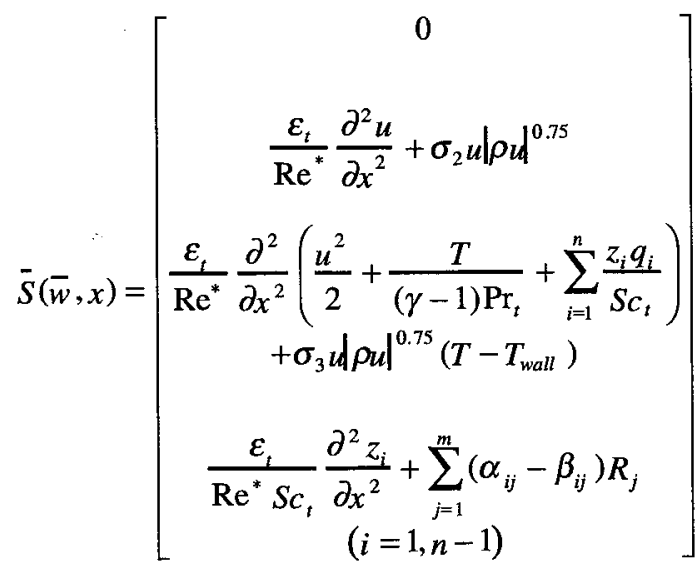

It contains contributions from the reactions, turbulent eddy diffusion, channel-wall viscous forces, and wall heat transfer. A leakage term added only for the endwall-adjacent gas is omitted here for clarity. The treatment of leakage, boundary conditions, heat transfer, and viscous losses in one-dimensional, finite-channelwidth, wave rotor calculations described in Ref. 10 is followed, with a modification given in Ref. 9. The eddy diffusion and wall-sources, and their coefficients $\sigma_{l}, \sigma_{2}$, $\varepsilon_{t}, \operatorname{Re}^{*}, P r_{t}, S c_{t}$ are as described in Ref. 9. $\beta_{i j}$ and $\alpha_{i j}$ are the stoichiometric coefficients for the mass of species $i$ participating as a reactant and product, respectively, in reaction $j$, which has rate $R_{j}\left(T, p, z_{i}\right)$, described below.

\section{Combustion Model and Reaction Rate}

In the calculations presented, combustion in the wave rotor is modeled by a single reaction step involving three species: 1 - fuel, 2 - oxidant (air), 3 - product. This is the simplest representation which allows for variable fuel-air ratio. The following discussion is a preamble to the formulation of an appropriate reaction rate.

In a simple finite-volume computation the thin moving reaction front, associated with the typically large activation energy of combustion reactions, cannot be resolved. Similarly, no account can be made of turbulence effects on scales smaller than the computational cell size and time step. Therefore, the reaction rates computed using cell-averaged variables must be assigned phenomenologically, based on a combination of chemical and turbulence effects. Turbulence effects are partly represented by the simple eddy diffusivity model.

The chemical kinetics of combustion must be modeled by choosing the reactions and species to consider. Even when a large 'full' set of chemical steps is used, the existence of flammability limits of reactant species concentrations cannot be accounted for without considering the physical processes that operate at extinction. ${ }^{12}$ The lean flammability limit has been accounted for when a heat loss model is added to a full kinetic calculation; however, this is still an area of active and often speculative research. Interestingly, the lean limit is not observed to be sensitive to the amount of heat loss. ${ }^{13}$ It appears to be related to a minimum energy content of reactants, so that the temperature of combustion products at the lean flammability limit is roughly a constant over a range of initial temperature of the mixture. This limit temperature is in the range of $1400-1600 \mathrm{~K}$ for hydrocarbon-air combustion. It allows for a simple total-energy-based flammability limit to be incorporated in the present model. 
The modeled reaction rate is determined by the minimum of three rates, each based on the concentration of one species, similar to Ref. 14. This implies that combustion will occur by a mixingcontrolled reaction at a propagating flame front at which all three species are present, with the most deficient species controlling the rate. The product species is given greater weight to account for its dominant role in providing active radicals (besides heat) for initiating reaction in the fuel-air mixture which is initially well below autoignition temperature. Fuel and air are weighted according to stoichiometry. Large activation energy is assumed, so that the classical Arrhenius model becomes an ignition-temperature model, i.e. the rate is zero below a threshold (ignition) temperature, $T_{i g n}$. Finite-volume computations based on a pure step function of the kind used in Ref. 9 were sometimes found to be unstable, magnifying small variations in local conditions. Therefore the rate is modeled by a factor with a power-law dependence on the excess temperature above $T_{i g n}$, which asymptotically tends to unity at high temperature.

A similar factor, and a limit temperature $T_{f l}$, is used in order to account for the fall in reaction rate close to the lean flammability limit and extinction below it. This factor introduces a rate-dependence on the 'total' static temperature, $T_{e}=T+(\gamma-1) z_{1} q_{1}$, which is the potential static temperature of the gas mixture after complete reaction, and therefore measures the total thermal and chemical energy of the mixture.

The rate of consumption of fuel species, incorporating the above features, is of the form:

$$
\begin{aligned}
R=K_{0} \rho\left\{\begin{array}{cc}
1-\left(T_{i g n} / T\right)^{l_{i g n}} & ; T>T_{i g n} \\
0 & ; T<T_{i g n}
\end{array}\right\} \times \\
\left\{\begin{array}{cc}
1-\left(T_{f l} / T_{e}\right)^{l_{f l}} & ; T_{e}>T_{f l} \\
0 & ; T_{e}<T_{f l}
\end{array}\right\} \times \\
\frac{1}{k_{\text {prod }}} \min \left\{\begin{array}{c}
z_{1} \\
z_{2} / \beta \\
\left.k_{\text {prod }} z_{3} /(1+\beta)\right)
\end{array}\right\}
\end{aligned}
$$

The subscript $j$ has been omitted as there is only one reaction step. The stoichiometric air/fuel mass ratio is $\beta$, so that the stoichiometric coefficients for three species are as follows; fuel: $\alpha_{1}=0, \beta_{1}=1$; air: $\alpha_{2}=0$, $\beta_{2}=\beta$; product: $\alpha_{3}=1+\beta, \beta_{3}=0$. The rate coefficient $K_{0}$ is to be specified based on the controlling turbulence timescale. Factor $k_{\text {prod }}$ assigns the product species weighting. For the ignition and flammability factors, values of the power-law exponent, $l$, in the range of 2 or 3 were found to work well. Fig. 3 is a graph of the temperature factor using these values.

\section{Numerical Method for Channel Flow and System}

The model numerically integrates the equations of motion in a single passage by the same method as described in Ref. 9, and will not be discussed in detail here. In essence it is a high-resolution, second-order scheme based on the approximate Riemann solver of Roe, ${ }^{11}$ with flux-limited dissipation. Grid-independent solutions were achieved with 200 computational cells in a channel length.

The channel flow equations are coupled to lumpedcapacitance models of the channel walls, leakage cavity, hot-gas-reinjection loop, and the downstream valved cavity representing the turbine. Since the time constants associated with transients in these objects are much longer than a complete wave cycle, their properties are updated once every cycle, until convergence to a steady-state and a periodic channelflow solution is obtained. Further details are provided in Ref. 9.

\section{Engine Design and Operating Range}

The simulations presented are for a pressure-gain wave rotor design intended for a small engine with an upstream compressor pressure ratio of approximately 8 , as was done in the previous study. The major design parameters of this rotor are listed in Table 1. Equivalent external-combustion pressure-exchanger designs are reported in References 5 and 15, which present performance predictions over a range of engine operating conditions. These studies predict that for a wave-rotor-topped engine in the $300 \mathrm{~kW}$ to $450 \mathrm{~kW}(400$ to $600 \mathrm{hp}$ ) class, specific fuel consumption (SFC) and

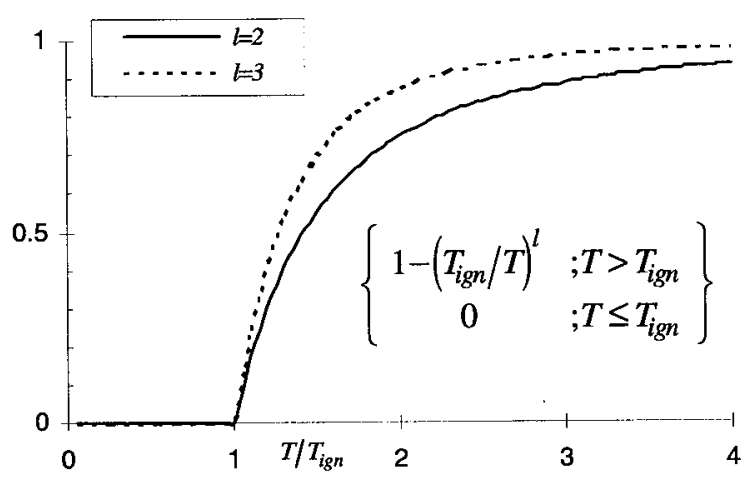

Fig. 3 Reaction Rate Temperature Factor 
Table 1 Wave Rotor Dimensions and Parameters

\begin{tabular}{lrr}
\hline \hline Mean Rotor Radius, $r$ & $8.15 \mathrm{~cm}$ & $(3.2 \mathrm{in})$ \\
Rotor Length, $L$ & $15.24 \mathrm{~cm}$ & $(6.0 \mathrm{in})$ \\
Rotor Channel Height & $2.18 \mathrm{~cm}$ & $(0.86 \mathrm{in})$ \\
Design Rotational Speed & $16,800 \mathrm{rpm}$ & \\
Cycles/revolution & 2 & \\
Number of Channels & 52 & \\
Inlet Area & $26 \mathrm{~cm}^{2}$ & $\left(4.0 \mathrm{in}^{2}\right)$ \\
\hline \hline
\end{tabular}

specific power can be enhanced significantly over the entire operating range. At the design point, the wave rotor produces a pressure gain of about $20 \%$ at the turbine inlet relative to the compressor discharge. This results in a specific power gain of $21 \%$ and SFC reduction of $17 \%$ over the baseline engine, similar to earlier predictions. ${ }^{1,6}$ Because of the self-cooling action of alternating hot and cold flow, the rotor is no hotter than the turbine and will use conventional materials.

In principle, a wave rotor with internal combustion will produce identical performance to a pressure-exchange wave rotor, if the inlet conditions from the compressor and exit conditions to the turbine are duplicated. However, the size and speed of the rotor may have to be adjusted to combustion requirements and this may result in differing performance. As discussed in Ref. 9, the requirement of completing combustion in a rotor of the given size and speed can be met with average turbulent flame speeds about $10 \mathrm{~m} / \mathrm{s}$ at the design point, assuming instantaneous ignition of each charge by reinjected hot gas and by residual hot gas. In this study, stratification of the charge into richer and shorter zones will result in faster combustion. As such, lower turbulence intensity and flame speed would yield similar combustion rates.

In a pressure-gain wave rotor discharging only to a high-pressure turbine, the channels cannot be completely purged with fresh cool air in each cycle. For maximum self-cooling and minimum size of an internal-combustion pressure-gain wave rotor, it should be designed to complete combustion as late as possible before exhaust, allowing for some cooler unburned gas to travel nearly the full length of the channels. ${ }^{9}$ Even then, the rotor will likely reach higher temperatures than an equivalent through-flow pressure-exchanger.

Three operating points are considered in this study: $100 \%$ design load, $40 \%$ load and idle. The pertinent nominal conditions for these three points are listed in Table 2. They are based on the pressure-exchanger designs of Refs. 5 and 15, and the fuel properties assumed in the next section.
Table 2 Topped-Engine Nominal Operating Conditions

\begin{tabular}{lrrr}
\hline \hline Load & Design & $40 \%$ & Idle \\
\hline Power (kW) & 520 & 220 & 0 \\
Mass Flow (kg/s) & 2.2 & 1.65 & 0.9 \\
Base Pressure Ratio & 7.6 & 5.4 & 2.5 \\
Heat Rate (kW) & 1800 & 1030 & 300 \\
Compressor Exit & & & \\
$\quad$ Temperature (K) & 600 & 540 & 420 \\
Overall fuel-air ratio & 0.020 & 0.015 & 0.008 \\
Turbine Inlet & & & \\
$\quad$ Temperature (K) & 1330 & 1100 & 700 \\
\hline \hline
\end{tabular}

\section{Simulations}

The reference state for non-dimensionalization of all variables at all conditions is the stagnation state of the compressor discharge (inlet to wave rotor) at the design conditions $\left(p^{*}=7.6 \mathrm{~atm}, T^{*}=600 \mathrm{~K}, a^{*}=485 \mathrm{~m} / \mathrm{s}\right)$. The simulations assume constant gas properties: specific heat ratio, $\gamma=1.353$, gas constant, $R=290 \mathrm{~J} / \mathrm{kg} / \mathrm{K}$, fuel lower heating value, $L H V=40 \mathrm{MJ} / \mathrm{kg}$, stoichiometric air/fuel ratio, $A F R_{s}=15$, and viscosity corresponding to a reference Reynolds number, $\operatorname{Re}^{*}=8.3 \times 10^{6}$, based on $a^{*}$ and rotor length, $L$.

For convenience, the chemical energy of the fuel is assigned the LHV: $q_{l}=170.0$, when nondimensionalized by $a^{* 2}$. The 'air' and 'product' species are therefore both at the zero-reference chemical energy level. Note that in a partially or fully combusted mixture, the 'air' species consists of all remaining oxygen and accompanying nitrogen in the same proportion as fresh air, and the 'product' species consists of reacted compounds and nitrogen in proportion to the consumed oxygen.

The turbulence and combustion rate parameters are kept fixed at the values given in Table 3 for all operating conditions. The values of these parameters cannot be justified a priori. They are chosen to be within the common range of turbulence levels and scales, and flame propagation rates observed in gas turbines and reciprocating engines utilizing hydrocarbon fuels. Nevertheless, combustion in wave rotors has unique features $^{8,9}$ for which little prior experience exists. These include flame distortion and likely acceleration by strong pressure waves, rotational effects, and relatively high-temperature proximate walls. Future wave rotor combustion experiments could be designed to calibrate the model presented by refining these parameter values. The choices of $\varepsilon_{t}$ and $K_{0}$ result in 
Table 3 Turbulence and Combustion Parameters

\begin{tabular}{lr}
\hline \hline Eddy/Molecular Viscosity Ratio, $\varepsilon_{t}$ & 1000 \\
Turbulent Prandtl Number, $P r_{t}$ & 1.0 \\
Turbulent Schmidt Number, $S c_{t}$ & 1.0 \\
Rate Coefficient, $K_{0}$ & 75.0 \\
Ignition Temperature (K), $T_{i g n}$ & 780.0 \\
Ignition Temperature Exponent, $l_{i g n}$ & 2.0 \\
Flammability Limit Temperature (K), $T_{f l}$ & 1560 \\
Flammability Limit Exponent, $l_{f l}$ & 3.0 \\
Product weighting factor, $k_{p r o d}$ & 0.1 \\
\hline \hline
\end{tabular}

apparent flame speeds that are consistent with turbulence intensity corresponding to about $1 \%$ of the kinetic energy in the inlet flow. The prescribed flammability limit temperature corresponds to a limit equivalence ratio of 0.54 for room temperature $(300 \mathrm{~K}$ ) reactants, and will translate to a lower equivalence ratio at higher reactant temperature $(0.34$ at $750 \mathrm{~K})$.

The stratification technique is illustrated in Fig. 4, in 'wave diagrams' of the flow-field for one cycle (half a revolution) of the wave rotor. These diagrams may be viewed as time traces of the flow in any one channel through one cycle, moving vertically upwards. Alternatively, they may be seen as time-averaged snapshots of the flow in all channels in an unwrapped half-circle of the rotor, with circumferential position, $\theta$, varying from 0 to $\pi$. From computations discussed in the next section, Fig. 4 has (a) a contour-line diagram of the pressure waves (isobars), superimposed over a grayscale contour-shade plot of the temperature (isotherms), and (b) a contour diagram of the fuel fraction with overlaid line and gray-scale plots. Lighter shades represent higher temperatures in (a), and higher fuel concentrations in (b). Observe the cyclic continuity of the variables in this converged periodic solution, from the top edge to the bottom edge of each diagram. Quantitative information about this and other simulations is presented later.

The charge stratification is arranged so as to ensure nearly complete combustion in all cases. The inlet port is divided into five equal circumferential sectors, comparable in width to the channel width, and the mixture strength is specified in each sector. Sector 1 supplies the first layer of gas to the channel, which relies on residual hot gas for ignition. Sector 5 supplies the terminal, wall-adjacent layer, which must be ignited by the reinjected hot gas from the passage fed by leading channels. The center sectors may be left unfueled, as long as fueled sectors are contiguous with ignited sectors, so that the two flame fronts propagating into the charge will reach all flammable mixture. The number of sectors was limited to five and made equal partly for computing convenience, and an actual design may use more sophisticated stratification. Finer stratification is generally not useful, considering that distortion of interfaces on the scale of the channel width will quickly diffuse the concentration gradient. However, finer stratification may be desired near the ignition sources to better control fuel concentration at ignition, before significant mixing can occur.

In addition to distributing the fuel such that each fueled sector contains a mixture within flammable limits, the equivalence ratio in Sector 5 is kept at 0.5 or higher, irrespective of inlet temperature. This gas when combusted supplies the reinjection passage (making up for leakage at the wall), and serves as the residual gas ignition source for the next inlet charge. This condition

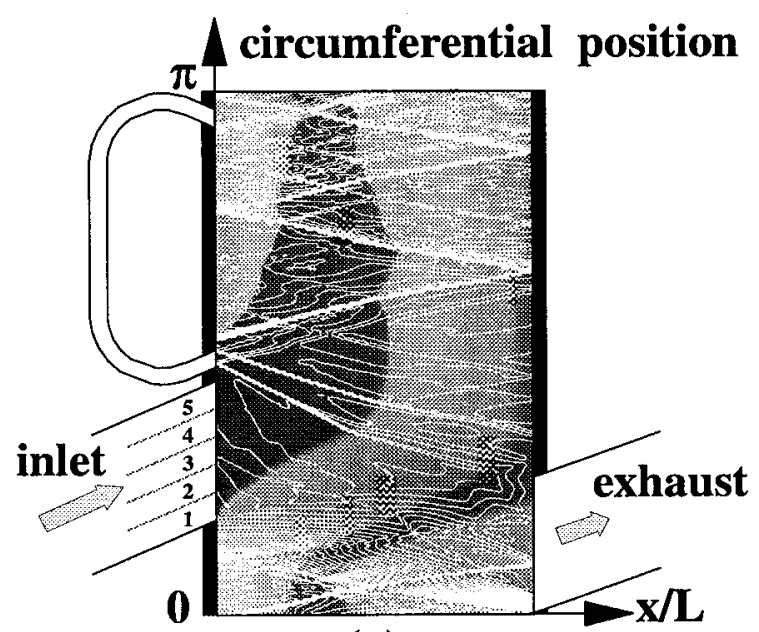

(a)

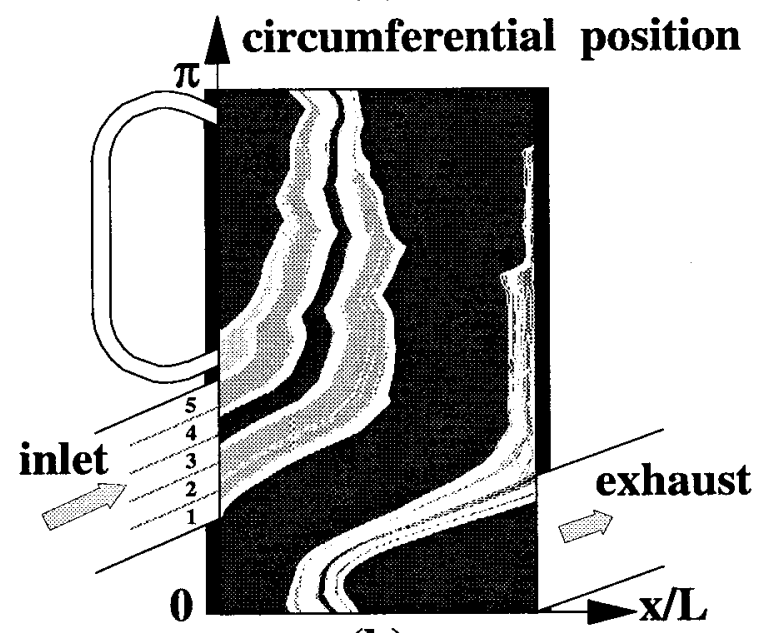

(b)

Fig. 4 Design point simulation contours: (a) temperature - shades, and pressure - lines, (b) fuel fraction 
will help ensure a lit combustor, but may not be sufficient to guarantee ignition under all conditions and provide minimum ignition delay for each fresh charge. It may be necessary to supply a very small quantity of additional fuel to the reinjection passage to attain near stoichiometric conditions in the relatively small mass flow in it (2-5\% of charge mass). This level of design detail is beyond the scope of this study.

The rotor speed is adjusted to attain the best wave timing, by visual inspection of the computed wave diagrams. The final converged solution is at a rotor speed such that there is no backflow when the inlet is opened, and the shock wave from the exhaust port arrives just after the inlet closes.

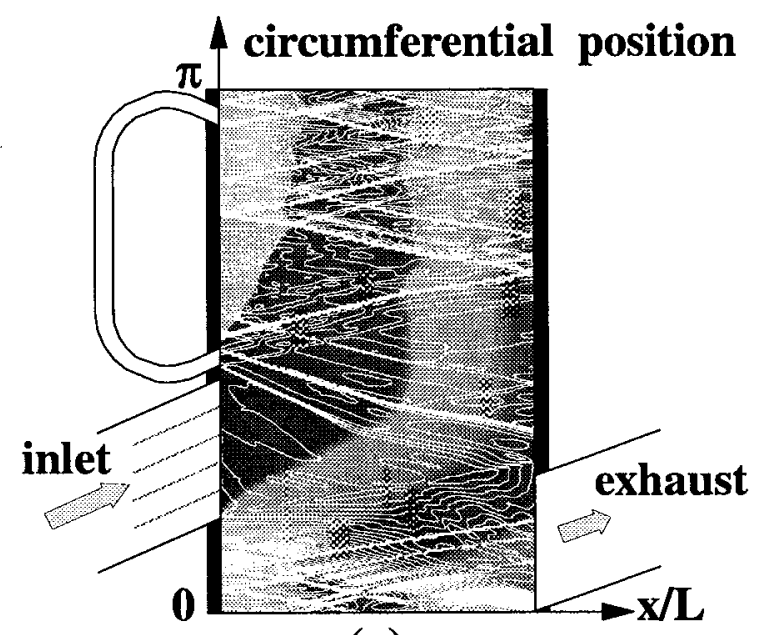

(a)

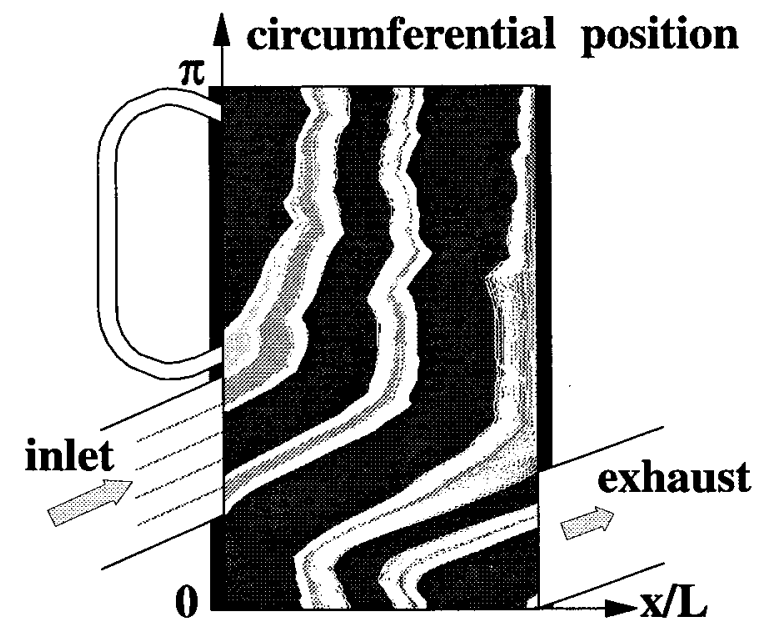

(b)

Fig. 5 Part-load point simulation contours: (a) temperature - shades, and pressure - lines, (b) fuel fraction

\section{$\underline{\text { Results }}$}

Wave diagrams for converged simulations are presented in Figures 4, 5, and 6, for the design point, part load (40\%), and idle operating conditions, respectively, of the engine. Corresponding to the observable pressure waves in the upper wave diagrams (a), representative time-traces of channel internal pressure over one cycle are given in Fig. 7 in which full lines are for pressure at the inlet (left) end of the channel, and the dashed lines are for the exhaust (right) end. With the rotor speed adjusted for load, it is seen that the wave pattern does not change qualitatively, although naturally, the highest pressures are generated at the highest load. If the ideal speed schedule is nearly proportional to the main shaft speed schedule, the wave rotor could be geared to it; otherwise, an electric drive motor is envisaged. In any

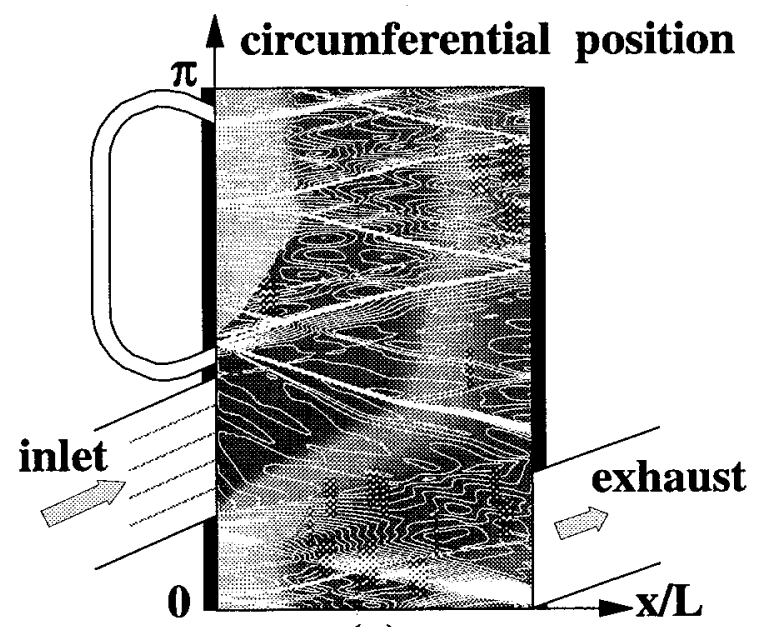

(a)

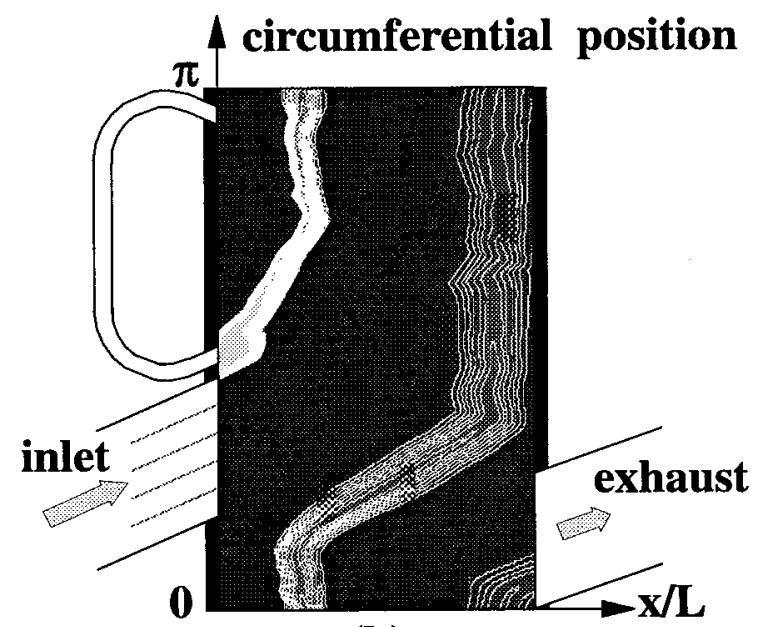

(b)

Fig. 6 Idle point simulation contours: (a) temperature - shades, and pressure - lines, (b) fuel fraction 
case, the drive power required will be minimal.

The position of the temperature discontinuity in the upper wave diagrams, between hot gas initially at the left end of the channel and the colder fresh inflow, indicates that approximately half the channel volume is purged and refilled in each cycle at all loads. The composition of the fresh gas at different loads and its change by combustion is qualitatively illustrated by the lower diagrams (b) in Figs. 4, 5, and 6. Note that the apparent slight mismatch between the port positions and gradients in the adjacent gas properties is due to the finite channel width and consequent gradual opening and closing of ports.

Quantitative information about the prescribed inlet stoichiometry, and the computed time-average velocity and temperature profiles in the inlet and the reinjection ports, are presented in Fig. 8 for each operating point. Corresponding plots of exhaust port profiles are given in Fig. 9. In these sets of plots velocity is scaled by the reference sound speed $\left(a^{*}=485 \mathrm{~m} / \mathrm{s}\right)$ and static temperature is in degrees Kelvin. Inlet stoichiometry and exhaust fuel concentration are both presented in terms of fuel/air equivalence ratio $(\phi)$, defined broadly to reflect fuel concentration:

$$
\phi=\frac{z_{1}}{\left(z_{2}+z_{3}\right)} A F R_{s}
$$

It will be observed that the stratification technique employed here results in a significant temperature gradient in the exhaust with generally higher temperatures in the leading side of the exhaust duct. It is also seen that there is a substantial amount of unburned fuel in the exhaust. The reason for this is that fuel which has diffused into adjacent unfueled air forms

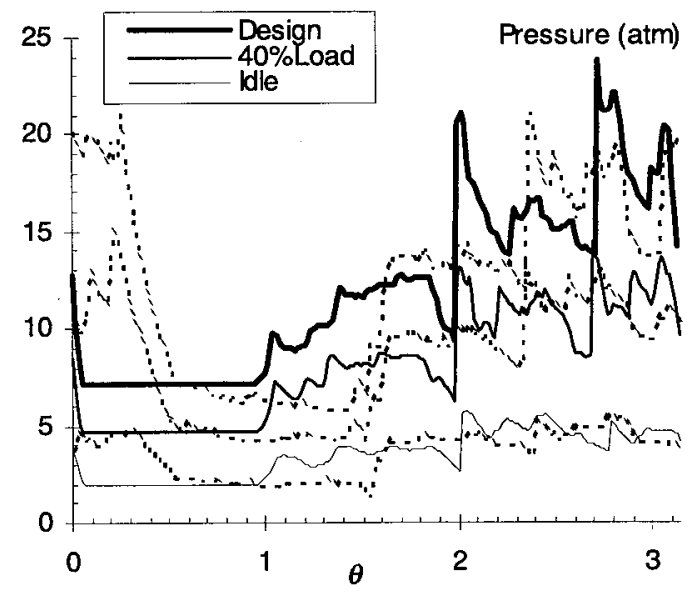

Fig. 7 Pressure traces for channel end gas
Table 4 Simulated Wave Rotor Performance and Temperature Data

\begin{tabular}{lrrr}
\hline Load & Design & $40 \%$ & Idle \\
\hline Speed, $N$ (rpm) & 16,800 & 14,400 & 13,200 \\
Wheel Mach No., $M_{w}$ & 0.29 & 0.27 & 0.28 \\
Mass Flow (kg/s) & 2.21 & 1.67 & 0.88 \\
Corrected Flow (kg/s) & 2.21 & 2.23 & 2.24 \\
Combustion $\eta(\%)$ & 91 & 77 & 80 \\
Pressure Gain (\%) & 23 & 13 & 3 \\
Exhaust Stagnation & & & \\
$\quad$ Temperature (K) & 1290 & 930 & 630 \\
Max. Turbine Inlet & & & \\
$\quad$ Temperature (K) & 1360 & 1060 & 680 \\
Cavity Temperature (K) & 1260 & 1200 & 870 \\
Cavity Pressure (atm) & 12.7 & 9.0 & 3.8 \\
\hline \hline
\end{tabular}

a mixture below the flammability limit, and will not be consumed. These two observations should be treated with caution as discussed in the next section.

The major performance measures and average exhaust conditions are listed in Table 4. As the load and rotor speed changes, the mass flow adjusts for speed, heat rate, and back pressure. The corrected mass flow and the wheel Mach number are defined, respectively as:

$$
\dot{m}_{c}=\dot{m} \frac{p^{*}}{p_{\text {in }}} \sqrt{\frac{T_{\text {in }}}{T^{*}}}
$$

and

$$
M_{w}=\frac{2 \pi r N}{60 a_{i n}}
$$

where $p_{i n}, T_{i n}$, and $a_{i n}$, are the stagnation pressure, temperature, and sound speed, respectively at the inlet to the wave rotor. Observe that the wheel Mach number and corrected flow do not change significantly with load. The pressure gain is the relative increase from compressor discharge to turbine inlet.

The maximum turbine inlet temperature indicated is the stagnation temperature if all residual fuel was reacted in the exhaust duct. The fuel rate was adjusted in an attempt to match the nominal turbine inlet temperature of Table 2. The pressure gain is penalized by incomplete combustion in the wave rotor, but the penalty for the design point combustion inefficiency does not appear to be significant in comparison to the complete-combustion calculations of Ref. 9. 


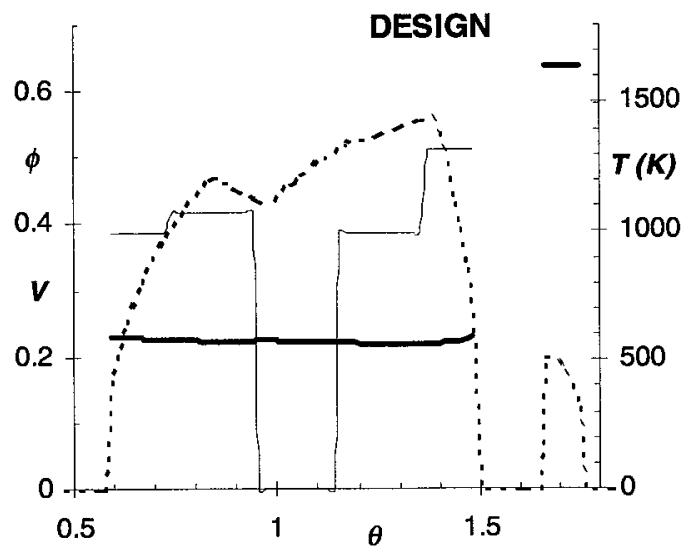

(a)

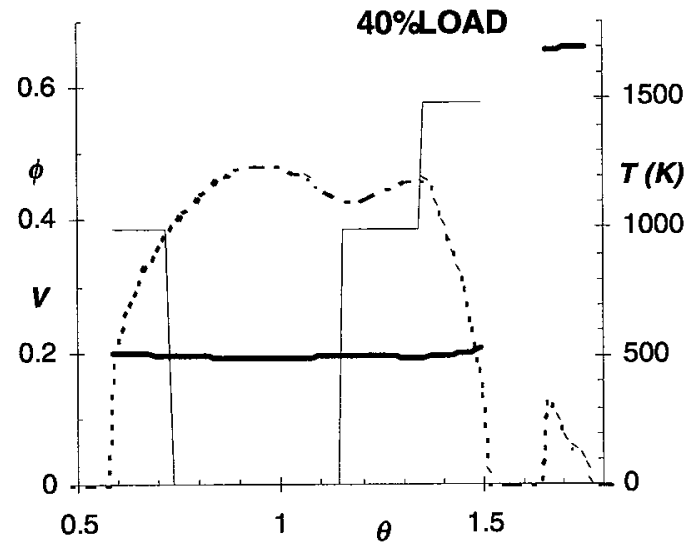

(b)

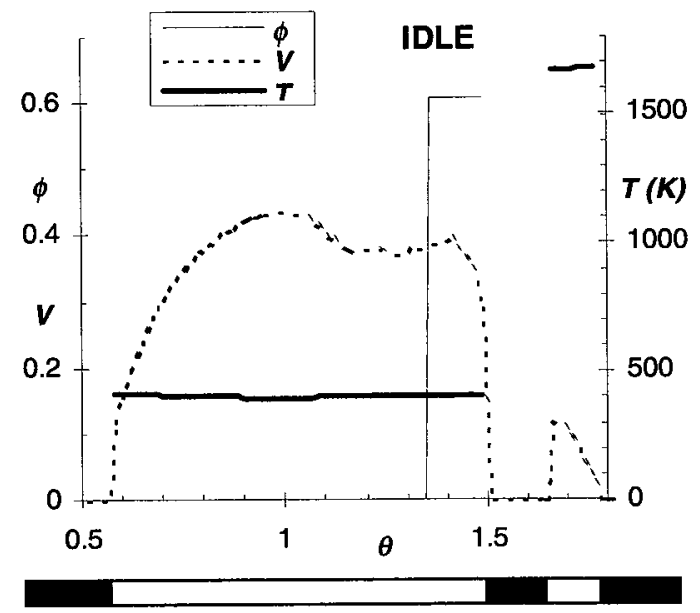

(c)

Fig. 8 Inlet and reinjection port profiles for equivalence ratio $(\phi)$, dimensionless velocity $(V)$, and static temperature $(T)$.

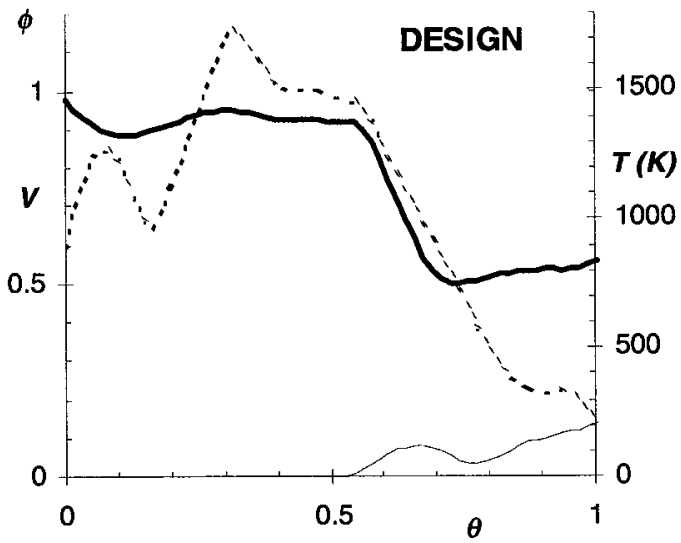

(a)

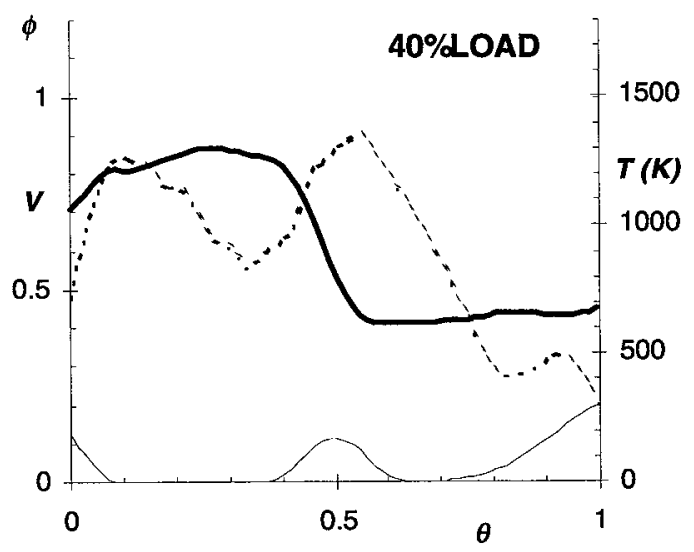

(b)

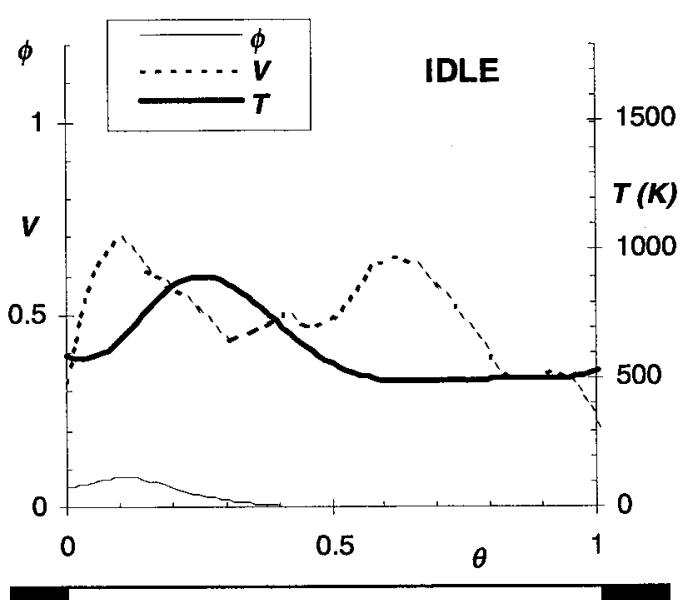

(c)

Fig. 9 Exhaust port profiles for equivalence ratio $(\phi)$, dimensionless velocity $(V)$, and static temperature $(T)$. 
The computed steady-state rotor wall temperature (assuming no axial conduction in the wall) is plotted in Fig. 10. At the design load, peak wall temperature exceeds the turbine inlet temperature only in a short segment of the rotor; if longitudinal conduction in the rotor is accounted for, the temperature everywhere should approach the mean rotor temperature, $1145 \mathrm{~K}$.

The temperatures of the gas adjacent to the end walls are plotted in Figs. 11 and 12, after averaging over fluctuations due to finite passage width. Here it is seen that the inlet side wall remains very hot throughout the load range, nearly $2000 \mathrm{~K}$ except near the inlet port itself. The exhaust side wall is considerably cooler, especially at lower loads. This should not surprise the discerning reader, as it is a consequence of the stratification strategy and gas particle paths revealed in the wave diagrams.

\section{Discussion}

The major impact of stratification, necessitated by the imposed flammability limits, is on the exhaust temperature profile and on the rotor and casing temperatures. These distributions of temperature in the device will have major implications for its thermomechanical design and integration with downstream turbomachinery. The gradients in exhaust temperature are attenuated by diffusion, but peak gas temperatures associated with ignition-zone stoichiometry will be above the design turbine-inlet temperature. The duct joining the wave rotor to the turbine must provide considerable mixing, driven by the velocity gradients and channel-to-channel fluctuations. To provide an acceptable radial pattern factor to the turbine it is desirable to orient remaining temperature variations in the circumferential direction. The duct aerodynamic design is strongly influenced by the decision regarding placement of the wave rotor on-axis or off-axis relative to the turbomachinery.

The rotor and end-wall temperature calculations are intended to illustrate the thermal issues related to design of internal-combustion wave rotors. The rotor temperature (without conduction) is seen to reach a maximum local value that just exceeds the turbine inlet temperature, but the average temperature is always well below this value. This result should be treated with caution, as it has been suggested in 2-d calculations ${ }^{16}$ that boundary-layer redistribution of fluid may result in temperatures near the wall that differ significantly from 1-d cell-averaged values. The results for the end walls are probably less disputable, and show that these can be extremely hot (up to $2000 \mathrm{~K}$ ). This is particularly so for the inlet-side which provides the recirculation of hot gas for ignition in the wall-adjacent gas. These walls will need special cooling methods, and sufficient thickness to minimize warping. The temperature of the exhaustside wall depends on the width of the central unfueled sector, and could be kept down even at higher loads by more skewed stratification, albeit at the expense of worsened exhaust port temperature variation.

Besides heating the end walls, the high gas temperatures at the leakage gap leads to the high cavity temperatures shown in Table 4. This could be a serious problem for temperature management of bearings, pressure walls, and other components. It is not feasible to purge this space, as cooler air is not available at a greater pressure than that created by leaking combustion gas.

Although the simulation results appear plausible, it is necessary to preface further discussion of their significance with some caveats about the simulation model. The use of a single turbulence parameter $\left(\varepsilon_{t}\right)$ to encapsulate all the complexities of free stream and boundary layer turbulence, large-scale vortical structures, and sub-grid flame structure of real flow in a wave rotor, is a major weakness of the simple eddy diffusivity model. It is recognized that gradientdiffusion models are truly applicable only to turbulent motions that have a scale smaller than the scale of the gradient zone itself. ${ }^{17}$ The combustion model based on this turbulence model suffers from this limitation as well. Although this is about the best one could expect with a one-dimensional grid, it necessarily requires circumspect interpretation of the results.

A number of mechanisms exist for generation of largescale turbulence. Pressure waves interacting with flames or other density gradients or discontinuities produce vorticity by baroclinic forces (RichtmyerMeshkov instability), and this can create large vortical structures, as borne out by two-dimensional wave rotor

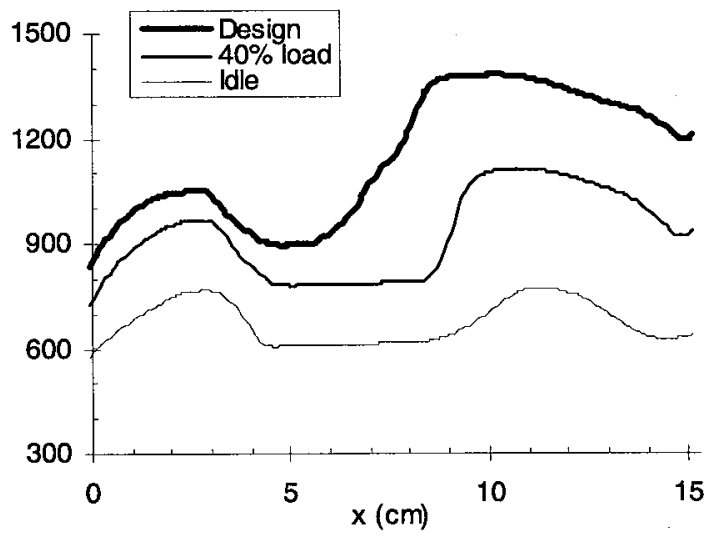

Fig. 10 Rotor Wall Temperature (K) 
flow calculations. ${ }^{16}$ Centripetal and Coriolis forces have a similar effect. Large-scale mixing also occurs when hot gas is reinjected at high speed to penetrate the fresh mixture over a distance greater than the channel width. Yet another mechanism for generation of such structures is the opening and closing of channels of finite width in the presence of significant pressure differences between the port and the channel. The partitions intended for stratification may add to stirring at the inlet plane. It can be shown that typical turbulence on the scale of the channel width will not dissipate significantly over the intake period of a wave cycle. ${ }^{8} \quad$ Fixed eddy diffusivity of the assumed magnitude probably overestimates small-scale mixing at the scale of the computational-cell size, but completely disregards large-scale stirring or redistribution (as distinct from mixing ${ }^{18}$ ). As the large structures break down, their energy reaches scales that beneficially promote mixing late in the cycle and in the exhaust duct.

These observations should imply that the combustion inefficiency associated with local diffusion of fuel to adjacent air may be exaggerated, and any such unreacted fuel will probably be stirred in with hot gas and burn up in the duct. This fuel energy released at duct pressure contributes nothing to pressure gain, but will be available to the turbine. The temperature gradients in the exhaust flow will then be less steep than shown. Nevertheless, the stratification will result in some temperature variation, and it appears from these simulations that the cooler gas is always concentrated at the trailing wall of the exhaust duct, where the flow velocity is relatively lower. Unless destroyed by stirring mechanisms, this consistent variation could be exploited to extract cooler gas for protection of the duct walls and possibly the turbine components. The availability of cooling air at sufficient pressure is a major issue in any pressure-gain scheme. It is

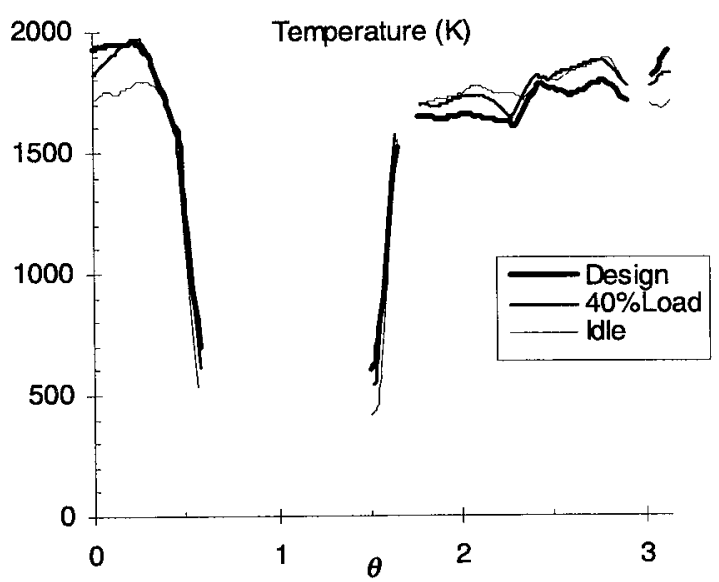

Fig. 11 Inlet-side End Wall Gas Temperature conceived that the hotter gas will be routed through an aerodynamically shaped liner to the turbine guide vanes, and the cooler gas will be directed to the space between the liner and the pressure wall.

The combustion model assumes virtually instantaneous ignition of fresh mixture by adjacent hot gas. This is kinetically plausible, the ignition process being more akin to intermittent pausing and resumption of a propagating flame rather than initiation of a new flame (as would be the case of electric spark ignition and flame kernel growth, a process which involves a long ignition delay). The chemical activity and active radical concentration levels of combustion products remains high for many milliseconds, long enough for even relatively slow IC engines to exploit for enhanced ignition. $^{19,20}$

The source of any ignition delay or extinction is more likely to be governed by the fluid mechanics of mixing, rather than chemistry. Excessive mixing due to freestream and inlet-generated turbulence may defeat the intent of stratification and create over-lean zones that will not react. Overzealous design of the reinjection of hot gas at too high velocity could retard ignition due to high initial strain rates. ${ }^{21}$ Thus, the hot gas recirculation passage design must be optimized to procure the gas at the right pressure for fastest re-ignition and combustion. It may turn out that the most effective recirculation of combustion products is from immediately preceding passages by the use of a pocket in the end wall, rather than by a duct from the highest pressure passages. Optimally, the Damkohler number (ratio of chemical to mixing timescales) must be near unity.

Cycle-to-cycle variability is a likely consequence of inconsistent ignition and combustion, and the stability issues discussed in Ref. 9 should be considered. To avoid the difficulties associated with hot gas leakage and reinjection, alternate ignition methods should be

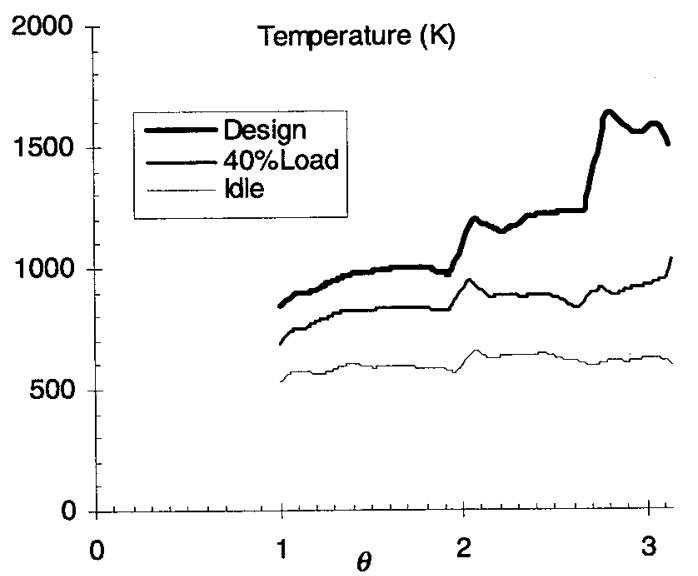

Fig. 12 Exhaust-side End Wall Gas Temperature 
investigated. These may include laser ignition, or ignition by rotor-based spark electrodes, which can initiate combustion in the interior of the channel rather than at the ends.

\section{Concluding Remarks}

A one-dimensional computational method for combustion in wave rotors has been further developed to allow rapid simulation of stratified premixed turbulent combustion. Flame propagation is simulated by the use of a mixing-controlled combustion model, based on a fixed eddy diffusivity. Multiple species and reaction steps are accommodated, and simple ignitiontemperature and mixture-flammability limits are incorporated. While the flow-loss models used are based on validated studies of non-reactive wave rotor flows, the combustion model awaits calibration by experiments or more detailed multi-dimensional calculations. Using plausible model parameters, simulations of combustion and flow are presented for operating points covering the full range of normal operation of a wave rotor combustor for a small turbine engine with nominal pressure ratio of 7.6 and turbine inlet temperature of $1300 \mathrm{~K}$. Although lacking the ability to resolve important flow features which may influence mixing and combustion, these 1-d simulations provide a general illustration of the issues facing internal-combustion wave rotor design.

The simulation results indicate that the goal of achieving high overall combustion rates within a small rotor appears feasible if fuel distribution is properly designed and actively controlled over the load range. A strategy for fuel-air mixture stratification is developed that appears to satisfy the requirements for cycle-tocycle reignition and adequate combustion rates and efficiency. Fuel is concentrated at the leading and trailing edges of the inlet port under load, and only at the trailing edge at idle. As load is varied, the speed of the driven rotor is adjusted over a narrow range, so that the cyclic wave pattern in the channels remains qualitatively similar. The assumption of a uniform fixed eddy diffusivity operating on the scale of the computational grid ignores large scale stirring mechanisms known to exist in wave rotors, which may modify the required stratification and the resulting flow and combustion processes.

The requirement for non-uniform fuel distribution leads to temperature profiles in the gas driving the turbine, and also affects the rotor temperature distribution and the end wall temperatures. Excessive local temperatures are generated that could negatively impact the rotor, housing, and downstream turbine. Peak rotor temperature will be comparable to the turbine inlet temperature, implying that similar materials could be used for construction of the turbine and wave rotor.

Of greater concern are the high temperatures of the gas near the end walls, which result in hot end walls (up to $2000 \mathrm{~K}$ if uncooled) and leakage of hot gas to the housing cavity. The cavity will reach $1260 \mathrm{~K}$ and 12.7 atm at full load, leading to possible overheating of sensitive areas, such as the pressure walls and rotor bearings, since there is normally no source for purging and cooling the space at these conditions. Warping of the end walls due to temperature non-uniformity will make leakage more difficult to control. Management of the end-wall temperature in particular, and thermal management of all other components of the system appear to be critical to the feasibility of this concept. Implications for the weight and durability of the rotating combustor, with its large pressure fluctuations, and of the entire system, must be explored further.

\section{Acknowledgments}

This work was performed while the author held a National Research Council - NASA Lewis Research Center Research Associateship. It would not have been possible without the considerable assistance of Dan Paxson of Lewis Research Center.

\section{$\underline{\text { References }}$}

1. Welch, G. E., Jones, S. M., and Paxson, D. E., "Wave Rotor-Enhanced Gas Turbine Engines," ASME Journal of Engineering for Gas Turbines and Power, vol. 119. p. 469, April 1997; also AIAA-95-2799, NASA TM-106998.

2. Nalim, M. R., Wave Cycle Design for Wave Rotor Engines with Limited Nitrogen Oxide Emissions, Ph.D. Thesis, Cornell Univ., Ithaca, NY, 1994.

3. Shreeve, R. P., and Mathur, A., (ed.), Proc. 1985 ONR/NAVAIR Wave Rotor Research and Technology Workshop, Naval Postgraduate School, Monterey, CA.

4. Nalim, M. R., "The Thermodynamic Limit of Pressure-Gain and Work-Producing Combustors", NASA Technical Memo., to be published, 1997.

5. Jones, S. M., and Welch, G. E., "Performance Benefits for Wave Rotor-Topped Gas Turbine Engines," ASME 96-GT-075, June, 1996; also NASA TM 107193, June, 1996.

6. Wilson, J., and Paxson, D. E., "Wave Rotor Optimization for Gas Turbine Engine Topping Cycles," Journal of Propulsion and Power, Vol. 12, No. 4, 1996, pp. 778-785; also NASA TM106951, May, 1995. 
7. Welch, G. E., Jones, S. M., and Paxson, D. E., 1995, "Wave Rotor Enhanced Gas Turbine Engines", AIAA paper 95-2799, NASA TM106998, ARL-TR-806.

8. Nalim, M. R., "Preliminary Assessment of Combustion Modes for Internal Combustion Wave Rotors", AIAA paper 95-2801, NASA TM$107000,1995$.

9. Nalim. M. R. and Paxson, D. E., "A Numerical Investigation of Premixed Combustion in Wave Rotors", ASME Journal of Engineering for Gas Turbines and Power, July 1997, in print. Also ASME-96-GT-116 and NASA TM-107242.

10. Paxson, D. E., "A Comparison Between Numerically Modeled and Experimentally Determined Wave-Rotor Loss Mechanisms," Journal of Propulsion and Power, Vol. 11, No. 5, 1995, pp.908-914; also NASA TM-106279, 1993.

11. Roe, P. L. "Characteristic Based Schemes for the Euler Equations," Annual Review of Fluid Mechanics, 1986, Vol. 18, pp. 337-65.

12. Strehlow, R. E., Combustion Fundamentals, McGraw-Hill, 1984.

13. Chen, Z. H. and Sohrab, S. H., "Flammability Limit and Limit-Temperature of Counterflow Lean Methane-Air Flames", Combustion and Flame, 102: 193-199, 1995.

14. Magnussen, B. F., and Hjertager, B. H., "On Mathematical Modeling of Turbulent Combustion with Special Emphasis on Soot Formation and Combustion", 16th Symposium (International) on Combustion, pp. 719-729, Combustion Inst., 1976.
15. Snyder, P. H., and Fish, R. E., "Assessment of a Wave Rotor Topped Demonstrator Gas Turbine Engine Concept," ASME 96-GT-041, June, 1996.

16. Welch, G. E., "Two-Dimensional Computational Model for Wave Rotor Flow Dynamics", ASME paper 96-GT-550; also NASA TM-107192 and ARL-TR-924, 1996.

17. Broadwell, J. E., and Breidenthal, R. E., "A Simple Model of Mixing and Chemical Reaction in a Turbulent Shear Layer", J. Fluid Mech., vol, 125, p. 397, 1982.

18. Broadwell, J. E., and Mungal, M. G., "Large-scale Structures and Molecular Mixing," Phys. Fluids A, 3 (5), p. 1193, May 1991.

19. Gussak, L. A., "High Chemical Activity of Incomplete Combustion Products and a Method of Prechamber Torch Ignition for Avalanche Activation of Combustion in Internal Combustion Engines", SAE paper 750890, Oct., 1975.

20. A Preliminary Study of Chemically Enhanced Autoignition in an Internal Combustion Engine", SAE paper 940758, Feb., 1994.

21. Cattolica, R., and Vosen, S., "Combustion Torch Ignition: Fluorescence Imaging of $\mathrm{OH}$ Concentration", Combustion and Flame, 68: 267$281,1987$. 
Public reporting burden for this collection of information is estimated to average 1 hour per response, including the time for reviewing instructions, searching existing data sources, gathering and maintaining the data needed, and completing and reviewing the collection of information. Send comments regarding this burden estimate or any other aspect of this Davis Highway, Suite 1204, Arlington, VA 22202-4302, and to the Office of Management and Budget, Paperwork Reduction Project (0704-0188), Washington, DC 20503.
1. AGENCY USE ONLY (Leave blank)
2. REPORT DATE
July 1997
3. REPORT TYPE AND DATES COVERED
Technical Memorandum

4. TITLE AND SUBTITLE

Numerical Study of Stratified Charge Combustion in Wave Rotors

5. FUNDING NUMBERS

6. AUTHOR(S)

WU-505-26-33

M. Razi Nalim

7. PERFORMING ORGANIZATION NAME(S) AND ADDRESS(ES)

8. PERFORMING ORGANIZATION REPORT NUMBER

National Aeronautics and Space Administration

Lewis Research Center

Cleveland, Ohio 44135-3191

E-10815

9. SPONSORING/MONITORING AGENCY NAME(S) AND ADDRESS(ES)

10. SPONSORING/MONITORING AGENCY REPORT NUMBER

National Aeronautics and Space Administration

Washington, DC 20546-0001

NASA TM-107513

AIAA-97-3141

\section{SUPPLEMENTARY NOTES}

Prepared for the 33rd Joint Propulsion Conference and Exhibit cosponsored by AIAA, ASME, SAE, and ASEE, Seattle, Washington, July 6-9, 1997. M. Razi Nalim, National Research Council-NASA Research Associate at Lewis Research Center. Responsible person, M. Razi Nalim, organization code 5810, (216) 433-6187.

12a. DISTRIBUTION/AVAILABILITY STATEMENT

12b. DISTRIBUTION CODE

Unclassified - Unlimited

Subject Category 07

This publication is available from the NASA Center for AeroSpace Information, (301) 621-0390.

13. ABSTRACT (Maximum 200 words)

A wave rotor may be used as a pressure-gain combustor effecting non-steady flow, and intermittent, confined combustion to enhance gas turbine engine performance. It will be more compact and probably lighter than an equivalent pressureexchange wave rotor, yet will have similar thermodynamic and mechanical characteristics. Because the allowable turbine blade temperature limits overall fuel/air ratio to sub-flammable values, premixed stratification techniques are necessary to burn hydrocarbon fuels in small engines with compressor discharge temperature well below autoignition conditions. Onedimensional, unsteady numerical simulations of stratified-charge combustion are performed using an eddy-diffusivity turbulence model and a simple reaction model incorporating a flammability limit temperature. For good combustion efficiency, a stratification strategy is developed which concentrates fuel at the leading and trailing edges of the inlet port. Rotor and exhaust temperature profiles and performance predictions are presented at three representative operating conditions of the engine: full design load, $40 \% \mathrm{load}$, and idle. The results indicate that peak local gas temperatures will result in excessive temperatures within the rotor housing unless additional cooling methods are used. The rotor itself will have acceptable temperatures, but the pattern factor presented to the turbine may be of concern, depending on exhaust duct design and duct-rotor interaction.

\section{SUBJECT TERMS}

Wave rotor; Simulation; CFD; Combustion; Flammability; Gas turbine engine

15. NUMBER OF PAGES

\begin{tabular}{|c|c|c|}
\hline $\begin{array}{c}\text { 17. SECURITY CLASSIFICATION } \\
\text { OF REPORT } \\
\text { Unclassified }\end{array}$ & $\begin{array}{c}\text { 18. SECURITY CLASSIFICATION } \\
\text { OF THIS PAGE } \\
\text { Unclassified }\end{array}$ & $\begin{array}{c}\text { 19. SECURITY CLASSIFICATION } \\
\text { OF ABSTRACT } \\
\text { Unclassified }\end{array}$ \\
\hline
\end{tabular}

